\title{
Coronary CT angiography derived FFR in patients with left main disease
}

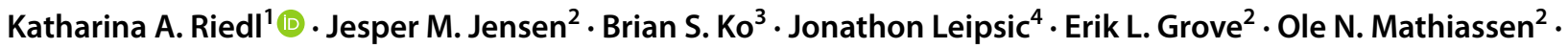 \\ Hans Erik Bøtker ${ }^{2} \cdot$ Bjarne L. Nørgaard ${ }^{2}$
}

Received: 24 March 2021 / Accepted: 3 August 2021 / Published online: 12 August 2021

(c) The Author(s) 2021

\begin{abstract}
The presence of left main coronary artery disease (LMCAD) is associated with an unfavorable clinical outcome. The clinical utility of $\mathrm{FFR}_{\mathrm{CT}}$ testing for non-invasive physiological assessment in LMCAD remains largely unknown. In this single center observational study LMCAD patients were retrospectively identified between November 2015 and December 2017. We evaluated the relationship between LMCAD diameter stenosis and downstream $\mathrm{FFR}_{\mathrm{CT}}$ values, and the clinical consequences following $\mathrm{FFR}_{\mathrm{CT}}$ testing in patients with LMCAD. The composite endpoint (all-cause death, myocardial infarction, unplanned revascularization) was determined over a median follow-up of 1.1 years. LMCAD was registered in 432 of 3202 (13\%) patients having coronary CTA. FFR $_{\mathrm{CT}}$ was prescribed in $213(49 \%)$, while 59 (14\%) patients were referred directly to invasive angiography or myocardial perfusion imaging. $\mathrm{FFR}_{\mathrm{CT}}$ was performed in 195 (45\%) patients. LM stenosis severity was inversely related to downstream $\mathrm{FFR}_{\mathrm{CT}}$ values. In patients with simple $\mathrm{LMCAD}$ with stenosis $\geq 50 \%,>80 \%$ had $\mathrm{FFR}_{\mathrm{CT}}$ $>0.80$ in non-diseased proximal and downstream segments $(n=7)$. No patients with simple LMCAD and FFR $\mathrm{CT}_{\mathrm{CT}}>0.80$ $(\mathrm{n}=20)$ suffered an adverse clinical outcome. FFR $_{\mathrm{CT}}$ testing in patients with LMCAD is feasible. LM stenosis severity is inversely related to $\mathrm{FFR}_{\mathrm{CT}}$ value. Patients with $\mathrm{LMCAD}$ and $\mathrm{FFR}_{\mathrm{CT}}>0.80$ have favorable clinical outcomes at short-term follow-up. Large-scale studies assessing the clinical utility and safety of deferring invasive catheterization following $\mathrm{FFR}_{\mathrm{CT}}$ testing in patients with LMCAD are warranted.
\end{abstract}

Keywords Computed tomography angiography $\cdot$ Coronary angiography $\cdot$ Coronary artery disease $\cdot$ Fractional flow reserve $\cdot$ Left main

Katharina A. Riedl

k.riedl@uke.de

Jesper M. Jensen

jesper.m.jensen@auh.rm.dk

Brian S. Ko

brian.ko@monash.edu

Jonathon Leipsic

jleipsic@providencehealth.bc.ca

Erik L. Grove

erikgrov@rm.dk

Ole N. Mathiassen

olemahia@rm.dk

Hans Erik Bøtker

heb@dadlnet.dk
Bjarne L. Nørgaard

bnorgaard@dadlnet.dk

1 Department of Cardiology, University Heart \& Vascular Center Hamburg, Martinistraße 52, 20246 Hamburg, Germany

2 Department of Cardiology, Aarhus University Hospital - Skejby, Aarhus, Palle Juul-Jensens Boulevard 69, 8200 Aarhus N, Denmark

3 Monash Cardiovascular Research Centre, Monash University and Monash Heart, Monash Health, 246 Clayton Rd, Clayton, VIC 3168, Australia

4 Department of Radiology, St. Paul's Hospital, University of British Columbia, 1081 Burrard St., Vancouver, BC V6Z1Y6, Canada 


\section{Introduction}

Left main coronary artery disease (LMCAD) is present in $4-7 \%$ of patients undergoing invasive coronary angiography (ICA) [1-3]. Since the presence of LMCAD with stenosis $>50 \%$ is associated with unfavorable clinical outcomes, characterization of the left main (LM) anatomy is crucial [4]. Several studies support the use of fractional flow reserve (FFR) to assess the hemodynamic consequences of LMCAD [5-8]. Coronary computed tomography angiography (CTA) is increasingly used as the first line test in patients with suspected coronary artery disease (CAD) $[9,10]$. However, as for ICA, CTA findings are often discordant with lesion-specific ischemia as determined by FFR, which currently remains the gold standard for decision-making during ICA [11]. CT-derived FFR $\left(\mathrm{FFR}_{\mathrm{CT}}\right)$ has emerged as a test with high diagnostic performance and correlation when compared with measured FFR $[11,12]$ and as a valuable gatekeeper to the catherization laboratory in patients with stable CAD [13, 14]. Recently, it has been demonstrated that $\mathrm{FFR}_{\mathrm{CT}}$ is effective in differentiating patients with stenosis who do not require further downstream testing or intervention $\left(\mathrm{FFR}_{\mathrm{CT}}>0.80\right)$ from higher risk patients in whom further testing and intervention should be considered $\left(\mathrm{FFR}_{\mathrm{CT}} \leq 0.80\right)$ [15-17]. However, the association between LMCAD and a normal $\mathrm{FFR}_{\mathrm{CT}}$ result has not previously been explored. Thus, the purpose of this study of patients with stable chest pain was two-fold: 1. to describe the relationship between LMCAD and $\mathrm{FFR}_{\mathrm{CT}}$ and 2. to evaluate the clinical utility of $\mathrm{FFR}_{\mathrm{CT}}$ in patients with LMCAD.

\section{Materials and methods}

This single-center, observational all-comer study included patients with LMCAD determined by CTA between November 2015 and December 2017 at Aarhus University Hospital, Denmark. The strategy of CTA as first line testing in symptomatic patients with suspected coronary artery disease (CAD) in this institution has previously been described $[14,15,18,19]$. In brief, CTA testing is the preferred diagnostic test strategy in patients with nonemergent chest pain and no known CAD such as previous revascularization. $\mathrm{FFR}_{\mathrm{CT}}$ testing is recommended in patients with one or more lesions of moderate stenosis severity (30 to $70 \%$ ) before decision-making on downstream management. Direct referral to ICA is generally recommended in patients with high risk anatomy including significant LMCAD, high grade proximal left anterior descending coronary artery (LAD) stenosis, and/or 3-vessel disease in this institution. However, other factors than test results (e.g. clinical presentation, patient preferences, and lesion characteristics) are also considered, when deciding the post-CTA patient management strategy [15]. Therefore, ICA may be deferred in some patients with "high-risk" anatomic features.

\section{Data sources}

Data were retrieved from 3 regional or national registries: 1. the Western Denmark Cardiac Computed Tomography Registry, containing information on the testing indication, patient demographics, CT acquisition characteristics, and CT test results [9], 2. the Danish National Patient Registry providing information on diagnoses, test utilization, and procedures from every hospitalization and outpatient clinical visits [9], and 3. the Civil Registration System, which contains complete data on mortality [9]. The study was approved by the Danish Data Protection Agency (1-16-02110-17) with a waiver for individual informed consent by the regional ethical committee.

\section{Coronary CTA}

Coronary CTA was performed using dual source scanners (Siemens Definition Flash or Siemens Definition Force, Siemens, Forchheim, Germany) as previously described [14, $15,18,19]$. In brief, scans were performed according to best CTA acquisition practice guidelines [20]. Oral and/or intravenous beta-blockers or oral ivabradine were administered if necessary, targeting a heart rate $<60$ beats/minute. Sublingual spray nitroglycerin $0.8 \mathrm{mg} 3$ to $5 \mathrm{~min}$ before the scan was administered in all patients. An initial non-enhanced high-pitch spiral acquisition scan was performed for assessment of the Agatston score. Coronary CTA acquisition was performed using prospective electrocardiographic triggering. In case of a heart rate of $<65$ beats/min a RR scan interval of 65 to $75 \%$ was applied and in case of a heart rate of $\geq 65$ beats/min the RR acquisition window was widened to 40 to $70 \%$. Vessels with a diameter $\geq 1.8 \mathrm{~mm}$ were evaluated for lumen narrowing. Coronary stenosis severity was categorized into four groups: $1-24 \%, 25-49 \%, 50-69 \%$, and $70-99 \%$. Stenosis severity $\geq 50 \%$ was definded as significant. Stenosis location was defined as proximal or distal as previously described [21]. Patients without a LM (separate ostia), and those with LM or proximal vessel occlusion were not included in this study. Cardiologists with a mean CTA interpretation experience of 7 years performed the readings.

\section{CTA-derived fractional flow reserve}

The science behind $\mathrm{FFR}_{\mathrm{CT}}$ has previously been described in detail [22]. Standard CTA datasets were transferred for 
off-site analysis as previously described (HeartFlow, Redwood City, California, US) [11]. A 3D FFR ${ }_{\mathrm{CT}}$ model provides computed FFR values in all segments with a lumen diameter $>1.8 \mathrm{~mm}$. A lesion with an $\mathrm{FFR}_{\mathrm{CT}}$ value $\leq 0.80$ was categorized as hemodynamically significant. From November 2015, a 3D interactive $\mathrm{FFR}_{\mathrm{CT}}$ model was available providing $\mathrm{FFR}_{\mathrm{CT}}$ values at all points of the coronary tree.

\section{LMCAD assessment}

In patients with simple LMCAD (isolated LM lumen diameter reduction between 1 and $99 \%$ with no $\geq 50 \%$ stenosis in the left major arteries), absolute $\mathrm{FFR}_{\mathrm{CT}}$ values were registered, 1. distally in the LM just proximal to the bifurcation when the distal border of the lesion was located $\geq 5 \mathrm{~mm}$ from the bifurcation, 2. in the proximal LAD and left circumflex artery (LCx) $1-2 \mathrm{~cm}$ distal from the bifurcation, and 3. in the distal LAD and distal LCx segments (Fig. 1). The first diagonal branch, and first obtuse marginal branch were used as delineators between proximal and non-proximal LAD and LCx segments, respectively. Distal FFR $\mathrm{CT}_{\mathrm{T}}$ values were assessed in the most distal LAD and LCx segments (with lumen diameter $>1.8 \mathrm{~mm}$ ). In patients with complex LMCAD (LMCAD with one or more significant $\geq 50 \%$ stenosis in non-LM coronary arteries), downstream FFR $_{\mathrm{CT}}$ was registered only in segments without stenosis $\geq 50 \%$. In patients with stenosis $\geq 50 \%$ in the proximal part of LAD or $\mathrm{LCx}, \mathrm{FFR}_{\mathrm{CT}}$ was only registered in the non-diseased vessel. An increase of the $\mathrm{FFR}_{\mathrm{CT}}$ value $\geq 0.03$ in mid-proximal relative to more the value in the LM was defined as pressure recovery. Patients with at least one severe lesion with $\mathrm{FFR}_{\mathrm{CT}}<0.65$ in either the proximal LAD or proximal LCx were excluded from the analysis, because FFR $<0.65$ in lesions located in proximal segments may influence the reliability of the FFR assessment of the LM [6,7].

\section{Clinical endpoint and follow-up}

We used a composite endpoint comprising all-cause death, myocardial infarction, and unplanned revascularization. Unplanned revascularization was defined as a procedure performed during an ICA which was not scheduled in the immediate post-CTA FFR $\mathrm{CT}_{\mathrm{T}}$ testing management plan. Follow-up began at the time of the CT scan and continued until the clinical event or end of the study period, June 18, 2018. There was no loss to follow-up during the study period.

\section{Statistics}

Categorical variables were described by counts and percentages. Groups were compared using Fisher's exact test. Continuous variables were described using mean \pm standard deviation (SD) or median (interquartile range, range) as appropriate.

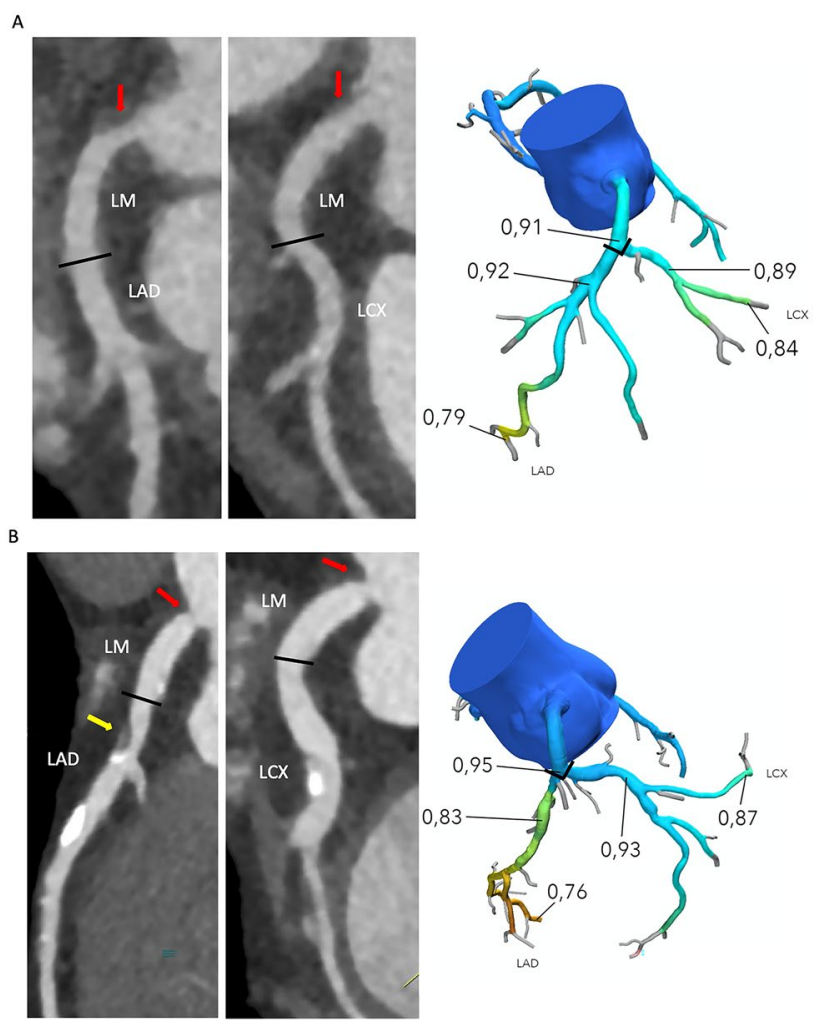

Fig. $1 \mathrm{FFR}_{\mathrm{CT}}$ reading strategy. Examples of patients with simple (A) or complex (B) left main coronary artery disease (LMCAD). FFR $_{\mathrm{CT}}$ was registered 1 . distally in the LM 2. in the proximal left anterior descending (LAD) and left circumflex artery (LCX) segments, and 3. distal segments. The first diagonal branch and first obtuse branch delineated proximal and non-proximal segments. Distal values were assessed in the most distal segments with lumen diameter $>1.8 \mathrm{~mm}$. In patients with simple LMCAD (A) $\mathrm{FFR}_{\mathrm{CT}}$ was registered in all segments 1-3. In patients with complex LMCAD (B) downstream $F_{C R}$ were registered only in non-stenotic arteries. Thus, $\mathrm{FFR}_{\mathrm{CT}}$ values in example B were registered only in the distal LM, and proximal and mid LCX segments. Left: Coronary CT angiography curved multiplanar reconstructions. Right: Three-dimensional $\mathrm{FFR}_{\mathrm{CT}}$ model. The red arrows indicate the location of LMCAD. The yellow arrow denotes a proximal $60 \%$ diameter stenosis in the LAD

Means were compared between the groups using the Student's t-test with unequal variance and medians were compared using Mann-Whitney U test. Means and medians between more than two groups were compared using the Kruskal-Wallis test. A p value $\leq 0.05$ was considered statistically significant. The endpoint analysis was estimated using the Kaplan Meier method. All analysis were performed using SPSS version 25 (SPSS Inc; Chicago, IL, US).

\section{Results}

During the study period, coronary CTA was performed in 3202 patients. LMCAD was registered in $432(13 \%)$ patients (Fig. 2). Post-coronary CTA direct referral to ICA 


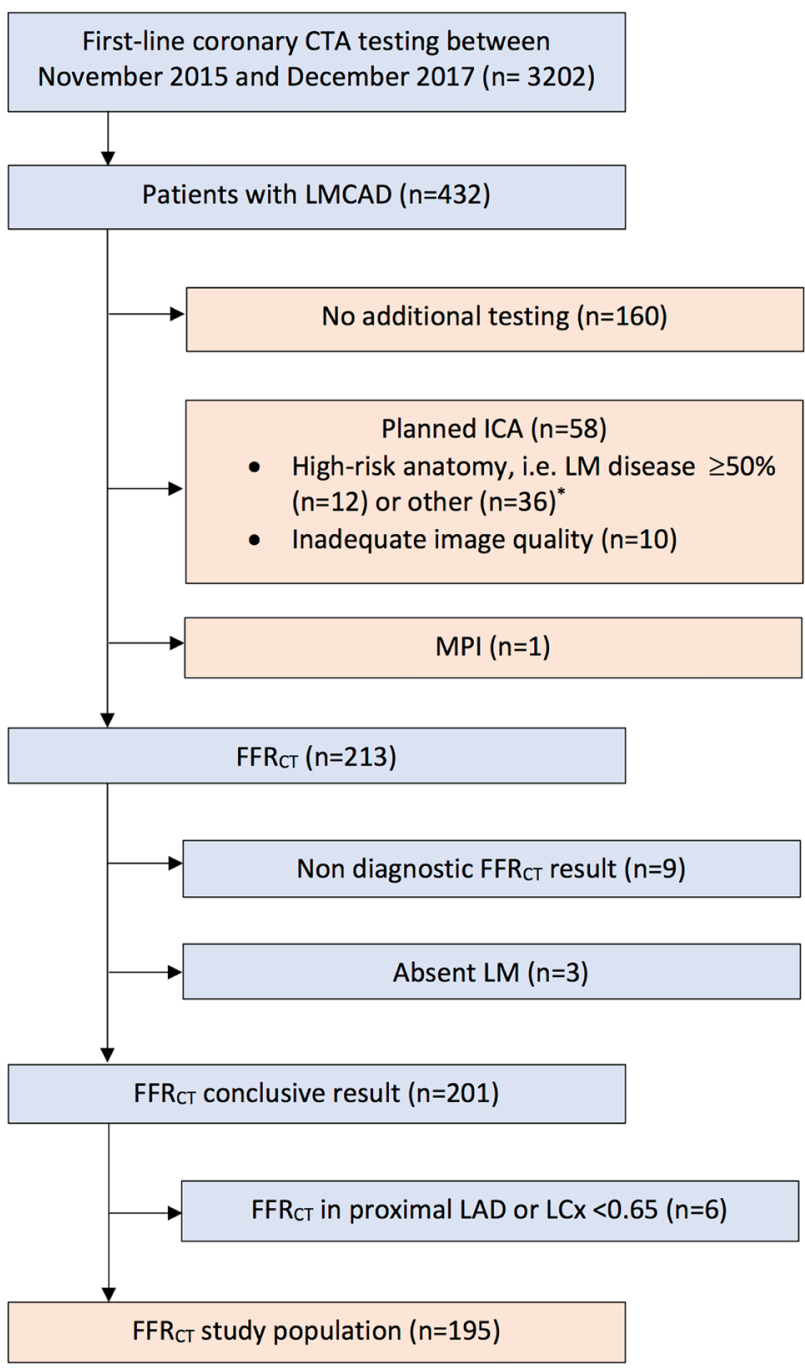

Fig. 2 Flow chart of study patients. CTA computed tomography angiography, $L M C A D$ left main coronary artery disease, ICA invasive coronary angiography, $M P I$ myocardial perfusion imaging, $F F R_{C T}$ coronary CTA-derived fractional flow reserve, $L M$ left main coronary artery, prox. Proximal, $L A D$ left anterior descending artery, $L C x$ left circumflex artery. *Patients with 3 -vessel disease. In patients with LMCAD stenosis $\geq 50 \%, 9$ had 3 -vessel disease

or myocardial perfusion imaging (MPI) was planned in 59 $(14 \%)$ patients. Of the remaining patients, $\mathrm{FFR}_{\mathrm{CT}}$ was prescribed in $213(49 \%)$ patients, while in $160(37 \%)$ patients no additional downstream testing was planned. A conclusive $\mathrm{FFR}_{\mathrm{CT}}$ result was available in $201(94 \%)$ patients. Coronary CTA image quality was inadequate for $\mathrm{FFR}_{\mathrm{CT}}$ analysis in $9(4 \%)$ patients, LM was absent in 3 patients, while in 6 patients the $\mathrm{FFR}_{\mathrm{CT}}$ value of the proximal LAD or LCx was $<0.65$ (Fig. 2). Therefore, 195 (45\%) patients with available $\mathrm{FFR}_{\mathrm{CT}}$ results comprised the basis of this report. Baseline patient characteristics are presented in Table 1. Mean (SD) age was $64( \pm 10)$ years, and $62 \%$ were men. Patients in the $\mathrm{FFR}_{\mathrm{CT}}$ group had a higher clinical risk score (Updated
Diamond-Forrester, $51 \%$ vs. $39 \%, \mathrm{p}<0.001$ ), and more frequently had typical angina $(58 \%$ vs. $15 \%, \mathrm{p}<0.001)$ than patients in whom $\mathrm{FFR}_{\mathrm{CT}}$ was not prescribed. Baseline anatomical characteristics of study patients are presented in Table 2. Patients in the $\mathrm{FFR}_{\mathrm{CT}}$ group had higher median Agatston scores than those in the no $\mathrm{FFR}_{\mathrm{CT}}$ group (351 vs. $47, p<0.001$ ), but lower than the group of patients who were referred directly to ICA or myocardial perfusion imaging ( 351 vs $535, \mathrm{p}=0.009$ ). Coronary CTA acquisition characteristics are presented in Table S1.

\section{Relationship between left main anatomy and downstream physiology}

In patients undergoing $\mathrm{FFR}_{\mathrm{CT}}$ testing, maximum LM stenosis ranged between $1-24 \%, 25-49 \%, 50-69 \%$ and $70-99 \%$ in $53 \%, 37 \%, 9 \%$ and $1 \%$, respectively. $\mathrm{FFR}_{\mathrm{CT}}$ values in the distal LM, proximal LAD, proximal LCx, distal LAD and distal LCx decreased with increasing LM stenosis severity (Table 3).

In patients with simple LMCAD $(n=21)$ and complex LMCAD $(n=174) \mathrm{FFR}_{\mathrm{CT}}$ values were significantly lower in the group with LM stenosis $\geq 50 \%$ versus those without stenosis (Table S2). Yet $\mathrm{FFR}_{\mathrm{CT}}$ in the $\mathrm{LM}$ was $>0.80$ in $95 \%(18 / 19)$ of the patients with maximum LM stenosis $\geq 50 \%$, including 7 (39\%) with simple LMCAD and 11 (61\%) with complex LMCAD, respectively. The proportion of patients with maximum LM stenosis $\geq 50 \%$, and $\mathrm{FFR}_{\mathrm{CT}}$ $>0.80$ decreased to $82 \%(9 / 11)$ when $\mathrm{FFR}_{\mathrm{CT}}$ was assessed in non-diseased proximal LAD and LCx segments. The number of patients with a significant $\mathrm{FFR}_{\mathrm{CT}}$ value was highest in the distal segments (Table S3).

In $3(2 \%)$ patients pressure recovery was identified; downstream $\mathrm{FFR}_{\mathrm{CT}}$ values $>0.80$ in all. One such case is presented in Fig. 3.

\section{Clinical outcomes}

The risk of the composite endpoint during follow-up was 5\% (Table 4). There was a numerically but not statistically significant difference in the risk of the composite endpoint when comparing the $\mathrm{FFR}_{\mathrm{CT}}$ and no $\mathrm{FFR}_{\mathrm{CT}}$ groups (5\% versus $1 \%, \mathrm{p}=0.15$ ) as shown in Table $\mathrm{S} 4$.

The risk of the composite endpoint, the number of ICA and of revascularization procedures in patients with simple or complex LMCAD based on the LM FFR $\mathrm{CT}_{\mathrm{CT}}$ values are presented in Table 4. There were no events in patients with simple LMCAD, of whom 7 of 8 with LM stenosis $\geq 50 \%$ had FFR $\mathrm{CT}>0.80$. The number of ICAs and revascularizations according to the anatomical findings and $\mathrm{FFR}_{\mathrm{CT}}$ results in patients with simple LMCAD are shown in Fig. S1. Patients with simple LMCAD with stenosis $\geq 50 \%$ having ICAs or revascularizations performed were more 
Table 1 Baseline characteristics

\begin{tabular}{lllllr}
\hline & $\begin{array}{l}\text { Total } \\
(\mathrm{n}=414)\end{array}$ & $\begin{array}{l}\mathrm{FFR}_{\mathrm{CT}} \\
(\mathrm{n}=195)\end{array}$ & $\begin{array}{l}\text { No further testing } \\
(\mathrm{n}=160)\end{array}$ & $\begin{array}{l}\text { ICA or MPI }^{\mathrm{a}} \\
(\mathrm{n}=59)\end{array}$ & $\mathrm{p} \mathrm{value}^{\mathrm{b}}$ \\
\hline Age, years & $64 \pm 10$ & $65 \pm 9$ & $62 \pm 10$ & $65 \pm 10$ & 0.03 \\
Male & $256(62)$ & $122(63)$ & $88(55)$ & $46(78)$ & 0.16 \\
Diabetes mellitus & $44(11)$ & $17(9)$ & $12(8)$ & $15(25)$ & 0.71 \\
Hypertension & $176(43)$ & $84(43)$ & $59(37)$ & $33(56)$ & 0.07 \\
Hyperlipidemia & $167(40)$ & $74(38)$ & $70(44)$ & $23(39)$ & 0.25 \\
Current smoker & $93(23)$ & $48(25)$ & $31(19)$ & $14(24)$ & 0.59 \\
Family history of CAD & $167(40)$ & $75(39)$ & $62(39)$ & $30(51)$ & 1.00 \\
Updated Diamond-For- & $47 \pm 21$ & $51 \pm 21$ & $39 \pm 18$ & $59 \pm 19$ & $<0.001$ \\
$\quad$ rester risk score, $\%$ & & & & & $<0.001$ \\
Angina & & & & $26(44)$ & \\
Typical angina & $99(24)$ & $58(30)$ & $15(9)$ & $27(46)$ & 0.50 \\
Atypical angina & $266(64)$ & $126(65)$ & $113(71)$ & $77 \pm 18$ & \\
Serum creatinine, $\mu \mathrm{mol} / 1$ & $79 \pm 21$ & $79 \pm 20$ & $77 \pm 18$ & \\
\hline
\end{tabular}

Values are mean \pm SD or numbers $(\%)$

$C A D$ coronary artery disease, $F F R_{C T}$ coronary CTA-derived fractional flow reserve, $I C A$ invasive coronary angiography, $M P I$ myocardial perfusion imaging

a Patients referred directly to ICA $(n=58)$ or MPI $(n=1)$ without $\mathrm{FFR}_{\mathrm{CT}}$

${ }^{\mathrm{b}}$ Comparison between the groups of $\mathrm{FFR}_{\mathrm{CT}}$ and No FFR $\mathrm{CT}_{\mathrm{C}}$

Table 2 Anatomical characteristics

\begin{tabular}{|c|c|c|c|c|c|}
\hline & $\begin{array}{l}\text { Total } \\
(\mathrm{n}=414)\end{array}$ & $\begin{array}{l}\mathrm{FFR}_{\mathrm{CT}} \\
(\mathrm{n}=195)\end{array}$ & $\begin{array}{l}\text { No further testing } \\
(\mathrm{n}=160)\end{array}$ & $\begin{array}{l}\text { ICA or MPI }^{a} \\
(n=59)\end{array}$ & $\mathrm{p}$ value ${ }^{\mathrm{b}}$ \\
\hline Agatston score & $\begin{array}{l}209 \\
(38-539,0-4904)\end{array}$ & $\begin{array}{l}351 \\
(130-737,0-4904)\end{array}$ & $\begin{array}{l}47 \\
(6-207,0-1394)\end{array}$ & $\begin{array}{l}535 \\
(221-1114,5-2940)\end{array}$ & $<0.001$ \\
\hline LM stenosis $1-24 \%$ & $274(66)$ & $104(53)$ & $141(88)$ & $29(49)$ & $<0.001$ \\
\hline LM stenosis $25-49 \%$ & $108(26)$ & $72(37)$ & $18(11)$ & $18(31)$ & \\
\hline LM stenosis $50-69 \%$ & $28(7)$ & $17(9)$ & $1(1)$ & $10(17)$ & \\
\hline LM stenosis 70-99\% & $4(1)$ & $2(1)$ & 0 & $2(3)$ & \\
\hline $\begin{array}{l}\text { LM stenosis } \\
1-49 \%\end{array}$ & & & & & $<0.001$ \\
\hline Simple LMCAD & $173(42)$ & $13(7)$ & $154(96)$ & $6(10)$ & \\
\hline Complex LMCAD & $209(51)$ & $163(84)$ & $5(3)$ & $41(70)$ & \\
\hline \multicolumn{6}{|l|}{$\begin{array}{l}\text { LM stenosis } \\
50-99 \%\end{array}$} \\
\hline Simple LMCAD & $9(2)$ & $8(4)$ & 0 & $1(2)$ & \\
\hline Complex LMCAD & $23(6)$ & $11(6)$ & $1(1)$ & $11(19)$ & \\
\hline
\end{tabular}

Values are numbers $(\%)$ or median (interquartile range, range)

$F F R_{C T}$ Coronary CTA-derived fractional flow reserve, ICA invasive coronary angiography, MPI myocardial perfusion imaging, $L M$ left main, $L M C A D$ left main coronary artery disease, Simple $L M C A D$ isolated left main disease, Complex LMCAD left main disease with one or more significant stenosis in non LM coronary arteries

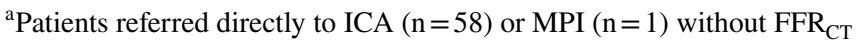

${ }^{\mathrm{b}}$ Comparison between the groups of $\mathrm{FFR}_{\mathrm{CT}}$ and No $\mathrm{FFR}_{\mathrm{CT}}$

likely to have numerically lower $\mathrm{FFR}_{\mathrm{CT}}$ values than those without ICA or revascularization.
In a subanalysis including the total $\mathrm{FFR}_{\mathrm{CT}}$ cohort and distal $\mathrm{FFR}_{\mathrm{CT}}$ values the risk of composite endpoint was $6 \%$ (7/126) vs. $3 \%(2 / 69)$ in patients with distal $\mathrm{FFR}_{\mathrm{CT}}$ value 
Table 3 FFR $_{\mathrm{CT}}$ values in the distal LM, proximal LAD and LCx and distal LAD and LCx according to LM stenosis severity

\begin{tabular}{|c|c|c|c|c|c|}
\hline \multirow[t]{2}{*}{ LM stenosis severity } & \multicolumn{4}{|c|}{$\mathrm{FFR}_{\mathrm{CT}}$ study population $(\mathrm{n}=195)$} & \multirow[t]{2}{*}{$\mathrm{p}$ value ${ }^{\mathrm{a}}$} \\
\hline & $1-24 \%(n=104)$ & $25-49 \%(n=72)$ & $50-69 \%(\mathrm{n}=17)$ & $70-99 \%(n=2)$ & \\
\hline $\begin{array}{l}\mathrm{FFR}_{\mathrm{CT}} \\
\text { distal LM }\end{array}$ & $\begin{array}{l}0.97 \\
(0.96-0.98,0.89-0.99) \\
\left(\mathrm{n}=104, \mathrm{FFR}_{\mathrm{CT}} \leq 0.80\right. \\
\quad \mathrm{n}=0)\end{array}$ & $\begin{array}{l}0.96 \\
(0.93-0.97,0.73-1.00) \\
\left(\mathrm{n}=72, \mathrm{FFR}_{\mathrm{CT}} \leq 0.80\right. \\
\mathrm{n}=2)\end{array}$ & $\begin{array}{l}0.91 \\
(0.85-0.95,0.70-0.98) \\
\left(\mathrm{n}=17, \mathrm{FFR}_{\mathrm{CT}} \leq 0.80\right. \\
\quad \mathrm{n}=1)\end{array}$ & $\begin{array}{l}0.87 \\
\left(\mathrm{n}=2, \mathrm{FFR}_{\mathrm{CT}} \leq 0.80\right. \\
\mathrm{n}=0)\end{array}$ & $<0.001$ \\
\hline $\mathrm{FFR}_{\mathrm{CT}}$ proximal LAD & $\begin{array}{l}0.95 \\
(0.93-0.96,0.88-0.99) \\
\left(\mathrm{n}=68, \mathrm{FFR}_{\mathrm{CT}} \leq 0.80\right. \\
\quad \mathrm{n}=0)\end{array}$ & $\begin{array}{l}0.93 \\
(0.89-0.94,0.72-0.98) \\
\left(\mathrm{n}=43, \mathrm{FFR}_{\mathrm{CT}} \leq 0.80\right. \\
\quad \mathrm{n}=3)\end{array}$ & $\begin{array}{l}0.90 \\
(0.79-0.94,0.67-0.95) \\
\left(\mathrm{n}=9, \mathrm{FFR}_{\mathrm{CT}} \leq 0.80\right. \\
\quad \mathrm{n}=3)\end{array}$ & $\begin{array}{l}0.84 \\
\left(\mathrm{n}=2, \mathrm{FFR}_{\mathrm{CT}} \leq 0.80\right. \\
\mathrm{n}=0)\end{array}$ & $<0.001$ \\
\hline $\mathrm{FFR}_{\mathrm{CT}}$ distal LAD & $\begin{array}{l}0.82 \\
(0.77-0.86,0.50-0.95) \\
\left(\mathrm{n}=68, \mathrm{FFR}_{\mathrm{CT}} \leq 0.80\right. \\
\quad \mathrm{n}=32)\end{array}$ & $\begin{array}{l}0.81 \\
(0.72-0.85,0.50-0.92) \\
\left(\mathrm{n}=39, \mathrm{FFR}_{\mathrm{CT}} \leq 0.80\right. \\
\quad \mathrm{n}=19)\end{array}$ & $\begin{array}{l}0.78 \\
(0.66-0.89,0.62-0.91) \\
\left(n=9, \mathrm{FFR}_{\mathrm{CT}} \leq 0.80\right. \\
\quad \mathrm{n}=5)\end{array}$ & $\begin{array}{l}0.62 \\
\left(\mathrm{n}=2, \mathrm{FFR}_{\mathrm{CT}} \leq 0.80\right. \\
\mathrm{n}=2)\end{array}$ & 0.23 \\
\hline $\mathrm{FFR}_{\mathrm{CT}}$ proximal $\mathrm{LCx}$ & $\begin{array}{l}0.96 \\
(0.94-0.97 \\
0.84-0.99) \\
\left(\mathrm{n}=87, \mathrm{FFR}_{\mathrm{CT}} \leq 0.80\right. \\
\quad \mathrm{n}=0)\end{array}$ & $\begin{array}{l}0.93 \\
(0.90-0.95 \\
0.74-0.98) \\
\left(\mathrm{n}=59, \mathrm{FFR}_{\mathrm{CT}} \leq 0.80\right. \\
\mathrm{n}=4)\end{array}$ & $\begin{array}{l}0.91 \\
(0.84-0.95 \\
0.67-0.97) \\
\left(\mathrm{n}=14, \mathrm{FFR}_{\mathrm{CT}} \leq 0.80\right. \\
\quad \mathrm{n}=1)\end{array}$ & $\begin{array}{l}0.82 \\
\left(\mathrm{n}=1, \mathrm{FFR}_{\mathrm{CT}} \leq 0.80\right. \\
\mathrm{n}=0)\end{array}$ & $<0.001$ \\
\hline $\mathrm{FFR}_{\mathrm{CT}}$ distal LCx & $\begin{array}{l}0.90 \\
(0.84-0.92,0.51-0.95) \\
\left(\mathrm{n}=86, \mathrm{FFR}_{\mathrm{CT}} \leq 0.80\right. \\
\quad \mathrm{n}=11)\end{array}$ & $\begin{array}{l}0.85 \\
(0.80-0.91,0.60-0.96) \\
\left(\mathrm{n}=60, \mathrm{FFR}_{\mathrm{CT}} \leq 0.80\right. \\
\mathrm{n}=17)\end{array}$ & $\begin{array}{l}0.85 \\
(0.77-0.93,0.61-0.95) \\
\left(\mathrm{n}=14, \mathrm{FFR}_{\mathrm{CT}} \leq 0.80\right. \\
\quad \mathrm{n}=6)\end{array}$ & $\begin{array}{l}0.79 \\
\left(\mathrm{n}=1, \mathrm{FFR}_{\mathrm{CT}} \leq 0.80\right. \\
\mathrm{n}=1)\end{array}$ & 0.03 \\
\hline
\end{tabular}

Values are median (interquartile range, range). Numbers in columns do not sum up to the total number of patients in each column header because in patients with complex LMCAD (LMCAD with one or more significant $\geq 50 \%$ stenosis in non-LM coronary arteries), downstream $\mathrm{FFR}_{\mathrm{CT}}$ values were registered only in segments without stenosis $\geq 50 \%$. In patients with stenosis $\geq 50 \%$ in the proximal part of LAD or LCx, $\mathrm{FFR}_{\mathrm{CT}}$ was only registered in the non-diseased vessel

$F F R_{C T}$ Coronary CTA-derived fractional flow reserve, $L M$ left main coronary artery, $L A D$ left anterior descending artery, $L C x$ left circumflex artery

${ }^{\mathrm{a} C}$ Comparison between all groups

$\leq 0.80$ and $\mathrm{FFR}_{\mathrm{CT}}$ value $>0.80$, respectively $(\mathrm{p}=0.09)$ (Table S5 and Fig. S2).

\section{Discussion}

In this study of consecutive symptomatic patients undergoing first line coronary CTA, LM stenosis severity was inversely related to $\mathrm{FFR}_{\mathrm{CT}}$ values irrespective of the reading point i.e. in the distal LM, or the proximal or distal LAD or LCx segments. In patients with simple LMCAD and stenosis $\geq 50 \%$, more than $80 \%$ had $\mathrm{FFR}_{\mathrm{CT}}>0.80$ in nondiseased proximal and distal LAD and/or LCX segments. $\mathrm{FFR}_{\mathrm{CT}}>0.80$ in patients with LMCAD was associated with favorable clinical outcomes.

Left main artery stenosis is associated with unfavorable outcomes. Therefore, societal guidelines emphasize the importance of revascularization of LM stenosis [23]. Although, FFR represents the gold standard for decisionmaking in the catherization laboratory, guidelines recommend that in the event of significant LM disease that treatment decision-making is guided by intravascular ultrasound
(IVUS) or optical coherence tomography (OCT) (IIa recommendation level) [23].

Patients with significant LMCAD were excluded from the FAME trials [24, 25], however preliminary data indicate that long-term outcome is more favorable in patients undergoing FFR than pure angiographically guided LM revascularization [8]. Assessing LM disease based on angiography or physiology is challenging due to the short length, catheter damping [26] and overlap of downstream vessels [27]. Moreover, downstream disease in the proximal LAD or LCx may influence the FFR values over LM stenosis potentially leading to false negative results $[7,28]$. Accordingly, it has been demonstrated that FFR $<0.65$ in lesions located in the proximal segments may influence the reliability of FFR assessment of LMCAD [6, 7].

Coronary CTA is increasingly used as the first line test in patients suspected of stable CAD, a strategy which is supported by guidelines [10]. Recently, the evidence for $\mathrm{FFR}_{\mathrm{CT}}$ has expanded beyond diagnostic validation [11, 12] by facilitating less referrals to ICA and less findings of non-obstructive disease in patients with moderate $\mathrm{CAD}$ [13-15]. Moreover, it has recently been demonstrated that patients with intermediate stenosis and $\mathrm{FFR}_{\mathrm{CT}}>0.80$ have 

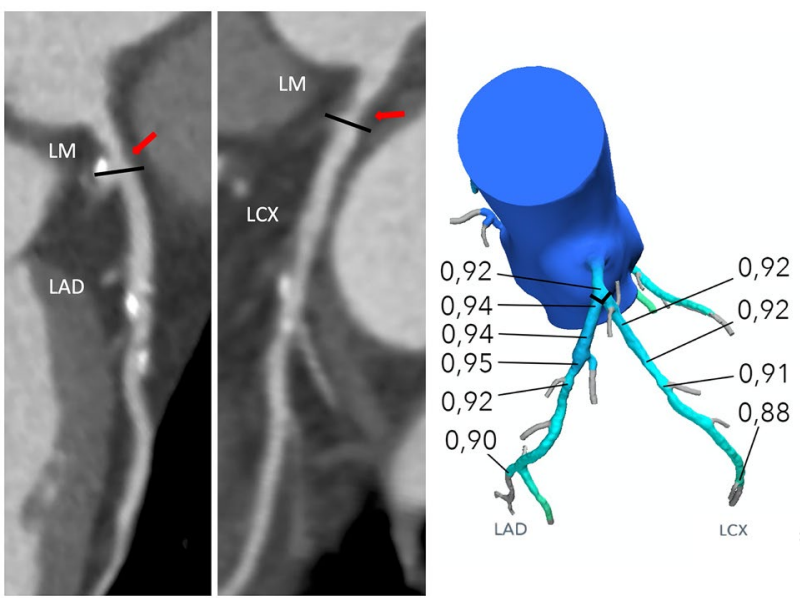

Fig. 3 Pressure recovery phenomenon. Typically, pressure will reach a minimum in the throat of stenosis with slight pressure recovery $0.5-1 \mathrm{~cm}$ distal to the stenosis because of the increase in the crosssectional area of the vessel and then decrease further downstream the vessel due to the continuous decrease in the cross-sectional area of the vessel and possibly the presence of flow limiting artery disease in more distal segments. However, $\mathrm{FFR}_{\mathrm{CT}}$ values may transiently rise also in segments located more distal to stenosis. In this case, the stepup in $\mathrm{FFR}_{\mathrm{CT}}$ from 0.92 distally in the left main (LM) to 0.95 in the mid left anterior descending artery (LAD) is caused by the presence of post-stenotic vessel dilatation resulting in reduced flow velocity and pressure recovery. We defined significant pressure recovery as an increase in $\mathrm{FFR}_{\mathrm{CT}} \geq 0.03$ when moving from the lesion-specific $\mathrm{FFR}_{\mathrm{CT}}$ "reading point" (typically $1-2 \mathrm{~cm}$ distal to the lower border of the stenosis) to more distal located segments. Coronary CT angiography curved multiplanar reconstructions. Right: Three-dimensional $\mathrm{FFR}_{\mathrm{CT}}$ model. Red arrow indicates the location of LMCAD. LCX left circumflex artery

favorable clinical outcomes without the need of further testing [15-17]. However, no previous study has investigated the potential clinical utility of $\mathrm{FFR}_{\mathrm{CT}}$ in patients with LMCAD. In this institution, patients with significant LM stenosis by coronary CTA are categorized as high risk and therefore per institutional practice it is recommended that such patients are referred directly to ICA, while in patients with non-obstructive LMCAD FFR $\mathrm{CT}_{\mathrm{T}}$ may be used for noninvasive hemodynamically adjudication. However, other circumstances than LM stenosis severity may have influenced downstream clinical decision-making in these patients, such as symptoms, other lesion anatomical characteristics, and patient preferences. Therefore, in this study $\mathrm{FFR}_{\mathrm{CT}}$ was used as an adjunctive test before decision-making on downstream management even in some patients with simple LM stenosis. In some of these patients, ICA was deferred based on a normal $\mathrm{FFR}_{\mathrm{CT}}$ result.

While FFR interrogation for assessment of LMCAD is performed in the proximal LAD and LCx segments [5] in this study, we also registered, $\mathrm{FFR}_{\mathrm{CT}}$ values in the distal LM. In accordance with previous findings we found that $\mathrm{FFR}_{\mathrm{CT}}$ values were inversely associated with LM stenosis severity

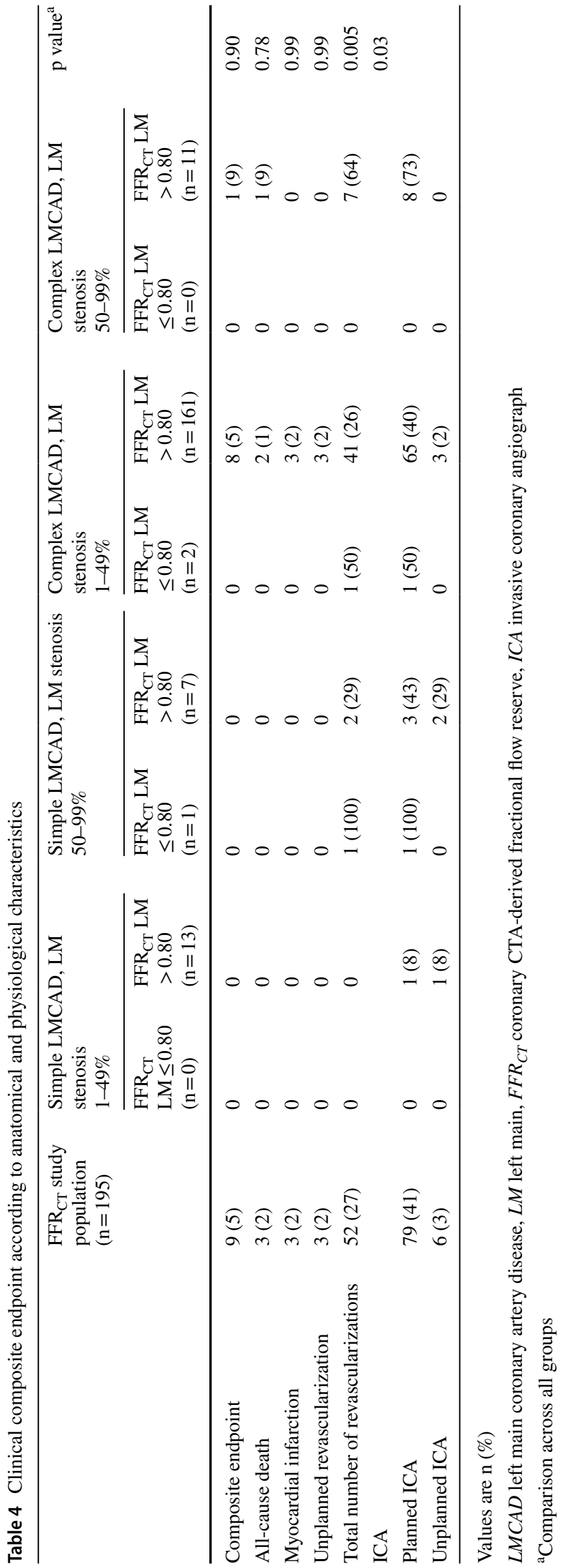


[15]. Moreover, $\mathrm{FFR}_{\mathrm{CT}}$ values were lower in distal than in proximal segments reflecting the fact that $\mathrm{FFR}_{\mathrm{CT}}$ is the sum of multiple downstream resistances from discrete lesions or diffuse disease. One striking finding was the low proportion of $\mathrm{FFR}_{\mathrm{CT}}$ positivity in significant $\mathrm{LM}$ stenosis, even among those with simple LMCAD with stenosis $\geq 50 \%$. In patients with simple LMCAD and stenosis $\geq 50 \%$ only $13 \%$ and $13 \%$ demonstrated $\mathrm{FFR}_{\mathrm{CT}} \leq 0.80$ when assessed distally in the LM or in proximal LAD and LCx segments. In comparison, in another real-world report from this institution, the proportion of stable patients with stenosis $\geq 50 \%$ in proximal segments and $\mathrm{FFR}_{\mathrm{CT}} \leq 0.80$ was $48 \%$ [15]. In a previous study assessing LMCAD physiology, it was demonstrated that significant stenosis or lesions in the downstream vessels may result in overestimation of FFR values [28]. However, since the low proportion of $\mathrm{FFR}_{\mathrm{CT}}$ positivity was present even in the event of minimal or absent downstream disease other mechanisms most likely play a role. The short length of the LM may potentially influence the atherosclerotic plaque formation and reliability of diameter stenosis assessment [29]. Rheological factors in very proximal LM stenosis may also play a role. At the entry of the left coronary system the blood flow is turbulent and pressure losses reduced compared to segments with laminar flow [29]. These findings need further delineation in future studies.

In contrast to FFR, which measures pressure at the location of the pressure wire, $\mathrm{FFR}_{\mathrm{CT}}$ values are available everywhere in the coronary tree. Thus, unlike invasive FFR, $\mathrm{FFR}_{\mathrm{CT}}$ may potentially be assessed in the LM stem. However, due to the short length of the LM it may be difficult in the majority of patients to obtain the value $10-20 \mathrm{~mm}$ distal to the lower border of stenosis, which is the location recommended for management actions [30]. A shorter distance between the lesion and the $\mathrm{FFR}_{\mathrm{CT}}$ reading point may potentially lead to more cases with pressure recovery which typically occurs just distal to a stenosis due to the increase in the cross-sectional area and corresponding loss in flow velocity (Bernoulli's principle) and then decreases again due to the continuous decrease in vessel area and/or downstream disease. The phenomenon was infrequently seen in this dataset, and thus could not explain the high number of $\mathrm{FFR}_{\mathrm{CT}}$ $>0.80$ in patients with $\mathrm{LM}$ stenosis $\geq 50 \%$.

Importantly, outcomes were favorable in patients with simple LMCAD and $\mathrm{FFR}_{\mathrm{CT}} \geq 0.80$. However, these findings are exploratory only and thus need confirmation in future studies. Overall, the proportion of patients with an adverse cardiac event during short-term follow-up was low. Notably, all adverse events occurred in patients with complex LMCAD. More studies are needed to assess the clinical utility of $\mathrm{FFR}_{\mathrm{CT}}$ in patients with LMCAD including exploration of the safety of deferring ICA in those with $\mathrm{FFR}_{\mathrm{CT}}>0.80$ as well as assessing the value of $\mathrm{FFR}_{\mathrm{CT}} \leq 0.80$ for decisionmaking on ICA and revascularization.
LM disease has traditionally required invasive angiography with or without FFR for determination of revascularization. CTA has up till now been deemed unable to adequately assess patients with LM disease. Potentially, the inherent risk of periinterventional complications in LMCAD patients may be reduced if safety of CTA-FFR $\mathrm{CT}_{\mathrm{T}}$ assessment for deferral of ICA in this setting can be confirmed in larger studies. This is a first description of the feasibility and clinical outcomes of $\mathrm{FFR}_{\mathrm{CT}}$ use in patients with LM disease. The present data are in accordance with recent data demonstrating the promise of extension of CTA use in more complex lesion subsets, and in those which had been previously deemed inappropriate or impossible for CTA testing [31, 32].

\section{Study limitations}

This is a single-center study with inherent limitations such as selection bias and possibly lack of generalizability of results. The number of patients with LM stenosis $\geq 50 \%$ was limited. However, the present study included an all-comer consecutive cohort of symptomatic patients, and thus is representative of patients encountered in clinical practice. In this study individual $\mathrm{CT}$ cardiologists prescribed $\mathrm{FFR}_{\mathrm{CT}}$ or ICA according to a varying degree of integrating test preferences and thresholds. We have no further information about reasons for sending some patients directly to ICA and not to $\mathrm{FFR}_{\mathrm{CT}}$ testing and vice versa. The proportion of patients with significant LMCAD or adverse clinical outcomes was low. Information of angina would have been valuable. Studies with more patients and longer follow-up are needed to confirm the present findings.

\section{Conclusions}

$\mathrm{FFR}_{\mathrm{CT}}$ testing in patients with LMCAD is feasible. LM stenosis severity is inversely related to downstream $\mathrm{FFR}_{\mathrm{CT}}$ values. Patients with $\mathrm{LMCAD}$ and $\mathrm{FFR}_{\mathrm{CT}}>0.80$ have favorable clinical outcomes at short-term follow-up. More studies assessing the clinical utility and safety of $\mathrm{FFR}_{\mathrm{CT}}$ testing in patients with LMCAD are warranted.

Supplementary Information The online version contains supplementary material available at https://doi.org/10.1007/s10554-021-02371-4.

\section{Acknowledgements None}

Funding Open Access funding enabled and organized by Projekt DEAL. This work was financially supported by the Faculty of Health Sciences, Aarhus University Hospital. 
Data availability The study data supporting the manuscript are available from the corresponding author upon approval of a reasonable request.

Code availability Not applicable.

\section{Declaration}

Conflict of interest This work was financially supported by the Faculty of Health Sciences, Aarhus University Hospital. Dr. JM Jensen and Dr. BL Nørgaard have received unrestricted research grants from Edwards Lifesciences, Siemens, and HeartFlow. Dr. EL Grove has received speaker honoraria or consultancy fees from AstraZeneca, Bayer, Boehringer Ingelheim, Bristol-Myers Squibb, Merck Sharp and Dohme, Pfizer, and Roche. Dr. J Leipsic has received speaker honoraria from GE Healthcare; served as a consultant for Edwards Lifesciences, and served as a consultant for and has stock options in Circle CVI and HeartFlow. All other authors have reported that they have no relationships relevant to the contents of this paper to disclose.

Ethical approval The study was approved by the Danish Data Protection Agency (1-16-02-110-17) with a waiver for individual informed consent by the regional ethical committee.

Open Access This article is licensed under a Creative Commons Attribution 4.0 International License, which permits use, sharing, adaptation, distribution and reproduction in any medium or format, as long as you give appropriate credit to the original author(s) and the source, provide a link to the Creative Commons licence, and indicate if changes were made. The images or other third party material in this article are included in the article's Creative Commons licence, unless indicated otherwise in a credit line to the material. If material is not included in the article's Creative Commons licence and your intended use is not permitted by statutory regulation or exceeds the permitted use, you will need to obtain permission directly from the copyright holder. To view a copy of this licence, visit http://creativecommons.org/licenses/by/4.0/.

\section{References}

1. Cohen MV, Gorlin R (1975) Main left coronary artery disease. Clinical experience from 1964-1974. Circulation 52(2):275-85

2. Noto TJ Jr, Johnson LW, Krone R, Weaver WF, Clark DA, Kramer JR Jr, Vetrovec GW (1991) Cardiac catheterization 1990: a report of the Registry of the Society for Cardiac Angiography and Interventions (SCA\&I). Cathet Cardiovasc Diagn 24(2):75-83

3. Fajadet J, Chieffo A (2012) Current management of left main coronary artery disease. Eur Heart J 33(1):36-50b

4. Yusuf S, Zucker D, Peduzzi P, Fisher LD, Takaro T, Kennedy JW, Davis K, Killip T, Passamani E, Norris R et al (1994) Effect of coronary artery bypass graft surgery on survival: overview of 10 -year results from randomised trials by the Coronary Artery Bypass Graft Surgery Trialists Collaboration. Lancet 344(8922):563-570

5. Hamilos M, Muller O, Cuisset T, Ntalianis A, Chlouverakis G, Sarno G, Nelis O, Bartunek J, Vanderheyden M, Wyffels E, Barbato E, Heyndrickx GR, Wijns W, De Bruyne B (2009) Long-term clinical outcome after fractional flow reserve-guided treatment in patients with angiographically equivocal left main coronary artery stenosis. Circulation 120(15):1505-1512

6. Daniels DV, van't Veer M, Pijls NH, van der Horst A, Yong AS, De Bruyne B, Fearon WF (2012) The impact of downstream coronary stenoses on fractional flow reserve assessment of intermediate left main disease. JACC Cardiovasc Interv 5(10):1021-1025

7. Fearon WF, Yong AS, Lenders G, Toth GG, Dao C, Daniels DV, Pijls NHJ, De Bruyne B (2015) The impact of downstream coronary stenosis on fractional flow reserve assessment of intermediate left main coronary artery disease: human validation. JACC Cardiovasc Interv 8(3):398-403

8. Mallidi J, Atreya AR, Cook J, Garb J, Jeremias A, Klein LW, Lotfi A (2015) Long-term outcomes following fractional flow reserveguided treatment of angiographically ambiguous left main coronary artery disease: a meta-analysis of prospective cohort studies. Catheter Cardiovasc Interv 86(1):12-18

9. Nielsen LH, Botker HE, Sorensen HT, Schmidt M, Pedersen L, Sand NP, Jensen JM, Steffensen FH, Tilsted HH, Bottcher M, Diederichsen A, Lambrechtsen J, Kristensen LD, Ovrehus KA, Mickley H, Munkholm H, Gotzsche O, Husain M, Knudsen LL, Norgaard BL (2017) Prognostic assessment of stable coronary artery disease as determined by coronary computed tomography angiography: a Danish multicentre cohort study. Eur Heart J 38(6):413-421

10. Moss AJ, Williams MC, Newby DE, Nicol ED (2017) The updated NICE guidelines: cardiac CT as the first-line test for coronary artery disease. Curr Cardiovasc Imaging Rep 10(5):15

11. Norgaard BL, Leipsic J, Gaur S, Seneviratne S, Ko BS, Ito H, Jensen JM, Mauri L, De Bruyne B, Bezerra H, Osawa K, Marwan M, Naber C, Erglis A, Park SJ, Christiansen EH, Kaltoft A, Lassen JF, Botker HE, Achenbach S (2014) Diagnostic performance of noninvasive fractional flow reserve derived from coronary computed tomography angiography in suspected coronary artery disease: the NXT trial (analysis of coronary blood flow using CT angiography: next steps). J Am Coll Cardiol 63(12):1145-1155

12. Driessen RS, Danad I, Stuijfzand WJ, Raijmakers PG, Schumacher SP, van Diemen PA, Leipsic JA, Knuuti J, Underwood SR, van de Ven PM, van Rossum AC, Taylor CA, Knaapen P (2019) Comparison of coronary computed tomography angiography, fractional flow reserve, and perfusion imaging for ischemia diagnosis. J Am Coll Cardiol 73(2):161-173

13. Douglas PS, Pontone G, Hlatky MA, Patel MR, Norgaard BL, Byrne RA, Curzen N, Purcell I, Gutberlet M, Rioufol G, Hink U, Schuchlenz HW, Feuchtner G, Gilard M, Andreini D, Jensen JM, Hadamitzky M, Chiswell K, Cyr D, Wilk A, Wang F, Rogers C, De Bruyne B (2015) Clinical outcomes of fractional flow reserve by computed tomographic angiography-guided diagnostic strategies vs. usual care in patients with suspected coronary artery disease: the prospective longitudinal trial of $\mathrm{FFR}(\mathrm{CT})$ : outcome and resource impacts study. Eur Heart J 36(47): 3359-3367.

14. Jensen JM, Botker HE, Mathiassen ON, Grove EL, Ovrehus KA, Pedersen KB, Terkelsen CJ, Christiansen EH, Maeng M, Leipsic J, Kaltoft A, Jakobsen L, Sorensen JT, Thim T, Kristensen SD, Krusell LR, Norgaard BL (2018) Computed tomography derived fractional flow reserve testing in stable patients with typical angina pectoris: influence on downstream rate of invasive coronary angiography. Eur Heart J Cardiovasc Imaging 19(4):405-414

15. Norgaard BL, Terkelsen CJ, Mathiassen ON, Grove EL, Botker HE, Parner E, Leipsic J, Steffensen FH, Riis AH, Pedersen K, Christiansen EH, Maeng M, Krusell LR, Kristensen SD, Eftekhari A, Jakobsen L, Jensen JM (2018) Coronary CT angiographic and flow reserve-guided management of patients with stable ischemic heart disease. J Am Coll Cardiol 72(18):2123-2134

16. Patel MR, Nørgaard BL, Fairbairn TA, Nieman K, Akasaka T, Berman DS, Raff GL, Hurwitz Koweek LM, Pontone G, Kawasaki T, Sand NPR, Jensen JM, Amano T, Poon M, Øvrehus KA, Sonck J, Rabbat MG, Mullen S, De Bruyne B, Rogers C, Matsuo H, Bax JJ, Leipsic J (2020) 1-year impact on medical practice and clinical outcomes of FFR(CT): the ADVANCE registry. JACC Cardiovasc Imaging 13(1 Pt 1):97-105 
17. Ihdayhid AR, Norgaard BL, Gaur S, Leipsic J, Nerlekar N, Osawa K, Miyoshi T, Jensen JM, Kimura T, Shiomi H, Erglis A, Jegere S, Oldroyd KG, Botker HE, Seneviratne SK, Achenbach S, Ko BS (2019) Prognostic value and risk continuum of noninvasive fractional flow reserve derived from coronary CT angiography. Radiology 292(2):343-351

18. Norgaard BL, Gormsen LC, Botker HE, Parner E, Nielsen LH, Mathiassen ON, Grove EL, Ovrehus KA, Gaur S, Leipsic J, Pedersen K, Terkelsen CJ, Christiansen EH, Kaltoft A, Maeng M, Kristensen SD, Krusell LR, Lassen JF, Jensen JM (2017) Myocardial perfusion imaging versus computed tomography angiography-derived fractional flow reserve testing in stable patients with intermediate-range coronary lesions: influence on downstream diagnostic workflows and invasive angiography findings. J Am Heart Assoc. https://doi.org/10.1161/jaha.117.005587

19. Norgaard BL, Hjort J, Gaur S, Hansson N, Botker HE, Leipsic J, Mathiassen ON, Grove EL, Pedersen K, Christiansen EH, Kaltoft A, Gormsen LC, Maeng M, Terkelsen CJ, Kristensen SD, Krusell LR, Jensen JM (2017) Clinical use of coronary CTA-derived FFR for decision-making in stable CAD. JACC Cardiovasc Imaging 10(5):541-550

20. Abbara S, Blanke P, Maroules CD, Cheezum M, Choi AD, Han BK, Marwan M, Naoum C, Norgaard BL, Rubinshtein R, Schoenhagen P, Villines T, Leipsic J (2016) SCCT guidelines for the performance and acquisition of coronary computed tomographic angiography: a report of the society of Cardiovascular Computed Tomography Guidelines Committee: Endorsed by the North American Society for Cardiovascular Imaging (NASCI). J Cardiovasc Comput Tomogr 10(6):435-449

21. Adjedj J, De Bruyne B, Flore V, Di Gioia G, Ferrara A, Pellicano M, Toth GG, Bartunek J, Vanderheyden M, Heyndrickx GR, Wijns W, Barbato E (2016) Significance of intermediate values of fractional flow reserve in patients with coronary artery disease. Circulation 133(5):502-508

22. Taylor CA, Fonte TA, Min JK (2013) Computational fluid dynamics applied to cardiac computed tomography for noninvasive quantification of fractional flow reserve: scientific basis. J Am Coll Cardiol 61(22):2233-2241

23. Neumann F-J, Sousa-Uva M, Ahlsson A, Alfonso F, Banning AP, Benedetto U, Byrne RA, Collet J-P, Falk V, Head SJ, Jüni P, Kastrati A, Koller A, Kristensen SD, Niebauer J, Richter DJ, Seferovic PM, Sibbing D, Stefanini GG, Windecker S, Yadav R, Zembala MO, Group ESCSD (2019) 2018 ESC/EACTS guidelines on myocardial revascularization. Eur Heart J 40(2):87-165

24. Tonino PA, De Bruyne B, Pijls NH, Siebert U, Ikeno F, van' t Veer M, Klauss V, Manoharan G, Engstrom T, Oldroyd KG, Ver Lee PN, MacCarthy PA, Fearon WF (2009) Fractional flow reserve versus angiography for guiding percutaneous coronary intervention. N Engl J Med 360(3):213-224

25. De Bruyne B, Pijls NH, Kalesan B, Barbato E, Tonino PA, Piroth Z, Jagic N, Mobius-Winkler S, Rioufol G, Witt N, Kala P, MacCarthy P, Engstrom T, Oldroyd KG, Mavromatis K, Manoharan G, Verlee P, Frobert O, Curzen N, Johnson JB, Juni P, Fearon WF
(2012) Fractional flow reserve-guided PCI versus medical therapy in stable coronary disease. N Engl J Med 367(11):991-1001

26. Pellicano M, Ciccarelli G, Xaplanteris P, Gioia GD, Milkas A, Colaiori I, Heyse A, Durme FV, Vanderheyden M, Bartunek J, Bruyne BD, Barbato E (2020) DISENGAGE registry. Circulation 13(11):8640. https://doi.org/10.1161/CIRCINTERVENTIONS. 119.008640

27. Puri R, Kapadia SR, Nicholls SJ, Harvey JE, Kataoka Y, Tuzcu EM (2012) Optimizing outcomes during left main percutaneous coronary intervention with intravascular ultrasound and fractional flow reserve: the current state of evidence. JACC Cardiovasc Interven 5(7):697-707

28. Yong AS, Daniels D, De Bruyne B, Kim HS, Ikeno F, Lyons J, Pijls NH, Fearon WF (2013) Fractional flow reserve assessment of left main stenosis in the presence of downstream coronary stenoses. Circ Cardiovasc Interv 6(2):161-165

29. Maehara A, Mintz GS, Castagna MT, Pichard AD, Satler LF, Waksman R, Laird JR Jr, Suddath WO, Kent KM, Weissman NJ (2001) Intravascular ultrasound assessment of the stenoses location and morphology in the left main coronary artery in relation to anatomic left main length. Am J Cardiol 88(1):1-4

30. Nørgaard BL, Fairbairn TA, Safian RD, Rabbat MG, Ko B, Jensen JM, Nieman K, Chinnaiyan KM, Sand NP, Matsuo H, Leipsic J, Raff G (2019) Coronary CT angiography-derived fractional flow reserve testing in patients with stable coronary artery disease: recommendations on interpretation and reporting. Radiology 1(5):50. https://doi.org/10.1148/ryct.2019190050

31. Collet C, Onuma Y, Andreini D, Sonck J, Pompilio G, Mushtaq S, La Meir M, Miyazaki Y, de Mey J, Gaemperli O, Ouda A, Maureira JP, Mandry D, Camenzind E, Macron L, Doenst T, Teichgraber U, Sigusch H, Asano T, Katagiri Y, Morel MA, Lindeboom W, Pontone G, Luscher TF, Bartorelli AL, Serruys PW (2018) Coronary computed tomography angiography for heart team decision-making in multivessel coronary artery disease. Eur Heart J 39(41):3689-3698

32. Linde JJ, Kelbæk H, Hansen TF, Sigvardsen PE, Torp-Pedersen C, Bech J, Heitmann M, Nielsen OW, Høfsten D, Kühl JT, Raymond IE, Kristiansen OP, Svendsen IH, Vall-Lamora MHD, Kragelund C, de Knegt M, Hove JD, Jørgensen T, Fornitz GG, Steffensen R, Jurlander B, Abdulla J, Lyngbæk S, Elming H, Therkelsen SK, Jørgensen E, Kløvgaard L, Bang LE, Hansen PR, Helqvist S, Galatius S, Pedersen F, Abildgaard U, Clemmensen P, Saunamäki K, Holmvang L, Engstrøm T, Gislason G, Køber LV, Kofoed KF (2020) Coronary CT angiography in patients with non-STsegment elevation acute coronary syndrome. J Am Coll Cardiol 75(5):453-463

Publisher's Note Springer Nature remains neutral with regard to jurisdictional claims in published maps and institutional affiliations. 